ounces. The last mentioned physiologist / conclusive evidence that the greater portion has determined the quantity of bile secreted of the whole bulk of the bile is reabsorbed by animals from its neutralising quality. from the alimentary canal.

Since the chyme is acid, and the whole of its acid becomes neutralised by the bile, it was only necessary to ascertain the quantity of chyme formed in order to determine the quantity of bile secreted. In this manner it was found that a large dog secretes about thirty-six ounces, and that horses must pour into the alimentary caval about $37 \mathrm{lbs}$., and oxen about $37 \frac{1}{2}$ lbs. of bile daily. Liebig adopts twenty-four ounces as the minimum of fluid bile secreted by man, which, calculating at 90 per cent. water, and 69 per cent. carbon in the dried bile, is not two ounces of carbon daily, but this is five times the quantity which could reach the liver in consequence of the change of matter in the body; hence it may be concluded that nonnitrogenised substances afford bile.

That, as a general rule, bile returns en" tirely into the circulation, and disappears completely, appears to be manifested in a variety of ways. In numerous animals provided with a biliary apparatus, which secretes bile abundantly, not one particle of this substance appears in the faces. In $\mathbf{1 0 0 0}$ parts of fresh buman fæeces Berzelius found only nine parts of a substance similar to bile. Supposing this to be bile, it will not account for more than one-fortieth or one-fiftieth part of the bile admitted by physiologists to be secreted by the liver of man. Bile, again, has been shown to be a compound of soda, but little or no soda appear's in the ashes of the fæces of animals. No picromel, nor choleic acid, nor any of the more abundant constituents of bile have been detected in fæcal matter. It is not for one moment imagined that the bile is absorbed as bile, nor should we mistake the colouring matter of bile for bile itself. It is the fluid compounds resulting from the admixture of bile with the chyme or with the contents of the alimentary canal which are absorbed. Although, after tying the ductus choledochus, a fluid some what resembling chyle is found in the lacteal system, there is every reason to believe that it is not perfect chyle. Even were it so, the bile in this case is carried by the lymphatics to the thoracic duct, and it may there perform all the changes attributed to its admixture with the products of the food, by Liebig, and by physiologists generally, having merely evaded, as it were, the alimentary cavity. Bile is absorbed from the alimentary canal, with other sulstances when used as an enema. Finally, Magendie believes that chyle may be produced by the ad. mixture of bile with the other intestinal fivids, without the presence of any chyme at all, as seems to be shown by the existence of a lactescent fluid in the lacteals of dogs kept without nourishment for periods varying from twelve to thirty-six hours. These considerations appear to me to afford pretty

If, then, the bile be a true native soap, if its alkali be soda, if it be secreted into the alimentary canal in large quantities, if it change the acescent part of the chyme into an opposite nature, and if the whole mass of the fluid be again "drunk up" from the alimentary and fæcal matters before they arrive at the anus, then were the views entertained respecting the bile during the last century, more correct in many important particulars, than those which have been in fashion during the greater portion of the present century. According to the opinions which formerly prevailed, the bile is of far greater importance in physiology and pathology than has more recently been taught in our medical schools, and this importance will be more than ever apparent, if Liebig's theory of the use of the elements of the bile during their ulterior circulation should be confirmed.

\title{
FIACTURE OF THE FEMUR AT EIGHTY-NINE YEARS OF AGE.
}

To the Editor.-Sir: Allow me to put on record the following instance, exhibiting the vis medicatrix natura favourably developed in the successful and speedy termination of fracture of the os femoris in a female subject of the great age of eighty-nine years :-

Sept. 10, 1842. Mrs. F, a meagre person, of temperate and regular habits, sustained a fracture of the left femur while, in the dusk of the evening passing across the road and coming in contact with a horse and light baker's cart, the driver of which did not observe her. On my seeing her, a few minutes afterwards, the nature of the injury was apparent. She was removed to her house, and the fracture ascertained to be oblique and near the centre of the bone.

Apparatus not being at hand she was placed in bed, and the limb encased in pillows, so as to form a double-inclined plane. On the next morning, September 11th, the fractured portions were placed in exact apposition, after considerable difficulty in retaining them in situ. The limb was put on the double-inclined plane formed by Macintyre's apparatus, with a long splint outside, and another, shorter, inside the thigh, each well padded. Thus was the extremity comfortably secured, and thus it remained without a single untoward or bad occurrence of consequence until October the 26th, the forty-fourth day, when the apparatus was removed, and the fractured part found to be firmly united, the tumour of callus being small, but sufficient to show the perfection of the cure and to allow motion of the limb in every direction. In a few days, by appropriate treatment, she was able to 
put her foot to the ground, and even step out, bearing the weight of the body. She has long ago been able to move without the aid of a stick, has been out of doors, and perfectly competent to take exercise on foot when the weather permits, no deformity ex isting in the parts.

This case is placed before the surgical world, particularly the junior portion, as a reason for not being dispirited in prognosticating osseous union in subjects far advanced in life, as, in the present instance, at first, it was pronounced to be not at all likely that any other than cartilaginous union would take place, and that therefore Mrs. F. would terminate her days as a cripple, from want of power in the system to unite the fractured bone. It is hoped its relation may call forth reports of any similar instances occurring in the practice of some of your numerous readers and correspondents. I am, Sir, your obedient servant,

W. F. Henderson, M.D., Surgeon.

Clapham-rise, Jan. 5, 1843.

\section{VAGINAL DISCHARGE}

IN

CHILOREN.

\section{IRON IN GLEET, ABSCESS, AND} DEBILITY.

To the Editor.-Sir: In answer to the inquiry of "C." (LANCET, Dec. 24), relative to the treatment of vaginal discharge in children, I beg to inform him that I have lately seen a case which readily yielded to calomel, rhubarb, and cinnamon, given every morning, employing, as au external application, a lotion composed of spirits and limewater, and which was afterwards changed for one made with the decoction of oak-bark and the tincture of galls.

I observe that Dr. Allnatt (page 504), in noticing this subject, advises the creosote injection for the cure of gleets, and as these cases are of some moment, perbaps I may be allowed to trouble you with the following:-About six months since, J. H., retat. 25, presenting a pale, pasty aspect, applied to me in consequence of suffering from a urethral discharge, the effect, he believed, of a gonorrhoea which he had contracted two years previously. He had been under the care of three London surgeons of some note; the ordinary injections had been used, and both the disulphate of quina and the steel mixture had been administered, without his experiencing much relief. The discharge had persisted for nearly two year's, was of a yellowish-white colour, and did not exceed more than a teaspoonful during the day. He was depressed in spirits, and "would give anything if he he could only get rid of it," as he was desirous of being married. I ordered him$\mathrm{R}$ Disulphate of quina, one scruple; citric acid, eighteen grains; best orange wine, twenty-six ounces. - Make a mixture, of which three tablespoonfuls are to be taken three times a day, with aloetic myrrh pill every other morning. This treatment was continued for a fortnight, and a cold silver catheter was passed every alternate day, but it appeared to exert no decided influence over his disease. I then directed him to take six drops of Mr. Tyson's "liq. ferri oxysulphatis," twice a-day, in a wineglassful of water, and prescribed the follow. ing injection, to be employed thrice daily :$\mathrm{B}$ Iodide of iron, four grains ; distilled water, eight ounces. The injection produced some pain, and at first appeared to increase the discharge, but in five days it had entirely ceased, and $\bar{l}$ believe has never returned. The internal exhibition of the iron was persevered in for a month, when, owing to his being attacked with catarrh, it was omitted.

A few weeks agro a man was admitted into the Casualty Hospital of this town who was afflicted with an old sinuous abscess, which was situated on the posterior region of the right thigh. It was laid open, pledgets of lint, dipped in a solution of iodide of iron, were inserted into the wound, and a poultice was applied. Free suppuration was speedily induced, its cavity became completely obliterated, and he was dismissed cured. In this instance the iodide of iron was also given internally. Might not a weak solution of this preparation be tried as an injection in obstinate leucorrhoea?

With regard to the "liq. ferri oxysul. phatis," I may mention that $I$ have taken it myself, combined with the infusion of calumba and wine of aloes, for the relief of debility, \&c., caused by tropical dysentery, and $I$ fancy that $I$ have derived benefit from it. Should it not be prepared with a less quantity of nitric acid than that ordered by Mr. Tyson? I am, Sir, yours obediently,

T. C. LEwIs.

Wolverhampton, January 10, 1843.

Oestinate Constipation. - In a recent debate, Dr. Chowne mentioned an inslance in which habitual constipation in an hysterical girl aged fourteen years, gave way before the internal use of croton oil, and injections of the same remedy. She had frequently gone a week without a motion; sometimes a fortnight, and, on one occasion, a month. In the same debate Dr. Reid stated that he had found, in a case of obstinate constipation in a young bysterical girl, that the most effectual way of producing an action of the bowels was to apply seven or eight leeches to the abdomen. This plan was found to be successful when all other means had been of no avail. Mr. Suow advocated the use of enemata of warm water in cases of obstinate constipation, the continual use of violent purgatives being liable to be followed by inflammatory mischief. 